\title{
Procesos de subjetivación en estudiantes de preparatoria como sujetos de derechos sexuales
}

\section{Subjectification processes of high school students as subjects of sexual rights}

DOl:https://doi.org/10.32870/dse.v0i21.722

\section{José Eduardo Ramírez Jiménez*}

\begin{abstract}
Resumen
Este artículo de investigación se refiere al proceso de subjetivación en el que estudiantes de preparatoria, pertenecientes a un plantel de Bachillerato General por Competencias de la Universidad de Guadalajara, se asumen como sujetos de derechos sexuales. Con el fin de contribuir a la discusión teórica, en este trabajo se expone la construcción del término sujetos de derechos sexuales. Los datos presentados son parte de un estudio más amplio, enfocado a conocer de manera integral dicho proceso, de manera particular se presentan tanto los significados que las y los jóvenes le asignan a la sexualidad y al "ser joven". Además, se muestran elementos del currículo que contribuyen a la subjetivación. El trabajo estuvo guiado por una metodología cualitativa y las técnicas utilizadas para la recolección de datos fueron la entrevista semiestructurada y la revisión documental. Los resultados indican que los significados son híbridos, en los cuales convergen diversos discursos.
\end{abstract}

Palabras claves: subjetivación - sujetos de derechos sexuales - significados - juventud - educación.

\begin{abstract}
This article refers to the subjectification process of high school students in the University of Guadalajara as subjects of sexual rights. The paper shows the construction of the term 'subject of sexual rights'. The data presented here are part of a wider study that explored the comprehensive process of this subjectification. It presents both the meanings that students attribute to sexuality and to youth, and also includes the elements of the curriculum that contribute to this subjectification. Our research was guided by a qualitative methodology, and the instruments for data collection were interviews and documentary reviews. The results indicate that the meanings are hybrids in which different discourses converge.
\end{abstract}

Key words: subjetictivation - subject of sexual rights - meanings - youth - education.

* Maestro en Investigación Educativa. Docente de bachillerato y licenciatura en la escuela UTEG. México. eduardo.ramirez111@gmail.com 


\section{Introducción}

Según diversas encuestas, las y los jóvenes de entre 15 y 19 años son sexualmente activos. ${ }^{1}$ A continuación se presentarán algunos datos que dan cuenta de un panorama sobre el ejercicio de la sexualidad.

La Encuesta Nacional de Dinámica Demográfica (ENADID, 2014) precisa que en el grupo poblacional etario entre los 15 y 19 años, 54.5\% reportó haber utilizado algún método de protección en su primera relación sexual, lo cual representa un incremento de 16.3 puntos porcentuales en relación con la ENADID 2009 (cuyo porcentaje fue de 38.2).

En el caso de Jalisco, de acuerdo con el Instituto Mexicano de la Juventud (2010), 52.6\% de las y los jóvenes del estado han tenido relaciones sexuales, la actividad sexual se inicia principalmente en el rango de edad de los 12 a los 17 años (57.2\%) y enseguida entre los 18 y los 23 años (39.6\%). Los hombres inician primero que las mujeres. Entre los motivos principales para tener relaciones sexuales se encuentran: por amor $(41.5 \%)$, por curiosidad $(24.2 \%)$ y porque desearon hacerlo (19.1\%). La mayoría reporta haber utilizado métodos anticonceptivos en la primera relación sexual (58.7\%), los hombres con $63.6 \%$ y las mujeres con $53.8 \%$. El método más utilizado es el condón (67.6\%) y el motivo más común para no utilizarlo es que las o los jóvenes no esperaban tener relaciones sexuales (59.7\%).

En el año 2017, de acuerdo con el informe del Early Institute, 774 niñas, niños y adolescentes fueron atendidos en un solo hospital por Infecciones de Transmisión Sexual (ITS). En este informe se afirma que existe una falta de datos para determinar la cantidad total de estos casos sobre ITS y violencia hacia esta población.

En lo referente a la reproducción, México tiene el primer lugar en Latinoamérica y el segundo en el mundo en tasa de embarazos de niñas y adolescentes. ${ }^{2}$ En el caso particular de Jalisco, el estado ocupa el quinto lugar de embarazos adolescentes a nivel nacional. De acuerdo con la Secretaría de Salud, casi 17\% de los nacimientos que ocurren en el estado son de madres de 19 años o menos. Este sistema precisa que el número de casos va en aumento. ${ }^{3}$

De 2016 a 2019, se estima que en México 422 mujeres han interrumpido el embarazo a causa de una violación sexual. Según las secretarías de salud, el rango de edad que más frecuentemente ha accedido a este servicio fue el de 15 a 19 años (119 mujeres). ${ }^{4}$ De acuerdo con un estudio realizado por el Colegio de México en el 2012, de las mujeres que han tenido un aborto

1 Instituto Jalisciense de la Juventud, 2010; Encuesta Nacional de Valores en Juventud, 2012; Encuesta Nacional de Salud y Nutrición, 2012 y la Encuesta Nacional de Dinámica Demográfica, 2015.

2 México ocupa segundo lugar a nivel mundial en embarazo adolescente (25 de septiembre del 2019). Milenio. https://www.milenio.com/ ciencia-y-salud/embarazo-adolescente-mexico-ocupa-mundo-latinoamerica

3 De madres adolescentes, $16.7 \%$ de nacimientos en Jalisco (3 de octubre de 2019). Unión Jalisco. https://www.unionjalisco.mx/articulo/2019/10/03/salud/de-madres-adolescentes-167-de-nacimientos-en-jalisco

4 Aborto. Un derecho que se regatea a las víctimas (2 de marzo del 2020). El Universal. https://www.eluniversal.com.mx/estados/aborto-underecho-que-se-regatea-las-victimas

Diólo@os 
inducido, las jóvenes entre 15 y 24 años representan cerca de la mitad del total de los casos. Lo anterior da pistas de las limitantes en las vías legales y en la carencia de recursos económicos para tener un aborto de manera segura.

Vistos desde una perspectiva de sexualidad integral y de derechos, el contagio de ITS, el embarazo, la maternidad y paternidad no deseados, y el aborto en condiciones inseguras se vinculan con el desconocimiento, la omisión del ejercicio o la violación de los derechos sexuales (Gutiérrez, 2003; Valenzuela y Casas, 2007; Pérez, 2007; Rodríguez, 2007; Sánchez, 2009). Para reducir las consecuencias negativas del ejercicio de la sexualidad es necesario hablar de sujetos que puedan decidir y actuar de manera responsable, placentera y segura (Checa, s.f.; Sánchez, 2009). En otras palabras, de personas que posean conocimientos tanto sobre sus derechos sexuales (DDSS, en adelante) como de sexualidad, y que ejerzan, exijan, demanden y promuevan dichos derechos. Es decir, de sujetos de derechos sexuales.

Con base en una búsqueda de investigaciones que se llevaron a cabo en México y Latinoamérica, se pudo dar cuenta que los derechos sexuales, en el ámbito educativo, se han abordado desde diferentes aristas, poblaciones y contextos. Se ha indagado sobre los conocimientos (Olivares y Trejo, 2010; Roncal y Carranza, 2012), las actitudes (Alva, 2006), el ejercicio (CDM, 2006) y la apropiación subjetiva (Amuchástegui y Rivas, 2004; Juárez, 2009; Ramos, 2011). Estos estudios se realizaron tanto en poblaciones rurales como en urbanas y participaron mujeres, jóvenes escolarizados (secundaria, bachillerato y universidad) y no escolarizados e indígenas. De estos, tres se llevaron a cabo dentro de contextos escolares: los realizados por el CDM (2006), Juárez (2009) y Roncal y Carranza (2012); el primero se hizo en Honduras en el nivel medio superior; el segundo en México, en el nivel básico (secundaria); y el tercero en Perú, en una universidad.

Como resultado de la búsqueda de investigaciones sobre derechos sexuales, se pudieron encontrar algunos vacíos en la generación de conocimiento. En primer lugar, pese a que las investigaciones revisadas consideran, tanto de manera implícita como explícita, a las personas como titulares de los derechos sexuales, estas no abordaron como objeto de estudio la subjetivación de las y los jóvenes como sujetos de derechos sexuales o las formas en que actúan como tales. En segundo lugar, ninguna de las investigaciones identificadas que se realizaron en instituciones escolares especifica si estas tienen planteado en sus programas de estudios el propósito de formar al sujeto de derechos.

Con base en la problemática antes mencionada, se planteó el objetivo general de describir de qué manera las y los jóvenes, estudiantes de una institución que tenga como propósito la formación de sujetos de derechos, devienen sujetos de derechos sexuales.

Antes de dar cuenta del objetivo general y de formular los objetivos específicos, se describirá un panorama del contexto sociocultural de las y los jóvenes, enseguida se presentarán las características del contexto educativo donde se realizó la investigación, y posteriormente se 
presentarán los conceptos y la reflexión teórica para definir el término sujeto de derechos sexuales y describir el proceso de formación y subjetivación en jóvenes estudiantes.

\section{Contexto sociocultural de las y los jóvenes}

En México, los derechos sexuales no existen explícitamente en el marco legal (Mesa, 2006; Olivares y Trejo, 2010; Castro, 2008; García, 2014). ${ }^{5}$ Sin embargo, al ser considerados como derechos humanos, sí se encuentran plasmados tanto de manera directa en los instrumentos internacionales adoptados por el país como de forma indirecta en la Constitución de los Estados Unidos Mexicanos y en diversas leyes y normas.

Las organizaciones civiles se relacionan de diferentes maneras con los DDSS. Se podrían identificar algunas que están en pro o en contra, e incluso algunas que apoyan algunos derechos y rechazan otros. Varias asociaciones civiles están enfocadas a la promoción del ejercicio, la defensa y la exigencia de condiciones y recursos, a través de la difusión de información e impartición de talleres para su promoción y defensa (por ejemplo, DDESER y Colectivo Ollin, en Jalisco). La participación de este tipo de organizaciones ha sido decisiva para lograr incluir el discurso de los DDSS en agendas políticas y para lograr su reconocimiento. Otras organizaciones reproducen discursos y realizan movilizaciones en contra de los DDSS de las y los jóvenes, tal es el caso de la Comisión Mexicana de Derechos Humanos, A.C. (CMDH). ${ }^{6}$

La ciudad de Guadalajara se ha caracterizado por tener una alta influencia del catolicismo, pues es la religión más profesada en el estado de Jalisco y ha tenido una fuerte incidencia en el debate de los DDSS. De acuerdo con Sánchez (2009), la Iglesia católica actúa de dos maneras sobre el campo de la sexualidad. La primera, realizando presiones políticas a estados nacionales y organizaciones internacionales para que se generen leyes que no contradigan sus concepciones religiosas. Sobre este último aspecto, Shepard (2004) precisa que la Iglesia católica busca promover "la buena moral" en la sexualidad, a través de la promoción de valores como la abstinencia hasta el matrimonio y la prohibición de cualquier forma de trasgresión a una "norma moral sagrada".

\section{Características del contexto educativo donde se realizó la investigación}

La elección del Sistema de Educación Media Superior (SEMS) de la Universidad de Guadalajara (UDG) se debió a que es la institución con mayor cobertura en el estado de Jalisco y por lo que se indica en el plan de estudios del Bachillerato General por Competencias (BGC).

5 Se encontró una referencia al concepto derechos sexuales en la Ley Federal para Prevenir y Eliminar la Discriminación.

6 Ballinas, V. y Becerril, A. (7 de noviembre del 2014). Eliminan los derechos sexuales de los menores y adolescentes de Ley General. La Jornada. http://www.jornada.unam.mx/2014/11/07/sociedad/049n2soc

Hernández, C. (7 de noviembre del 2014). Ley de infancia: un juego de palabras. Reporte ĺndigo.http://www.reporteindigo.com/reporte/mexico/ ley-de-infancia-un-juego-de-palabras

Diálo pos 
El SEMS de la Universidad de Guadalajara cuenta con la mayor cobertura en el estado de Jalisco. De acuerdo con la página de internet oficial de la institución, cuenta con 166 planteles ubicados en 109 municipios, en los que se tienen implementados 24 programas educativos basados en: una enseñanza por competencias, la demanda del mercado laboral y el uso de las tecnologías de la información y la comunicación. Estos programas son el Bachillerato General por Competencias (BGC), el Bachillerato General por Áreas Interdisciplinarias (BGAI) y 22 opciones de Educación Tecnológica (ET). En total, el SEMS cuenta con una matrícula de 139 mil alumnos. ${ }^{7}$

El plan de estudios del BGC indica que se busca dotar a las y los estudiantes de una cultura general para desempeñarse en los ámbitos científico, social, tecnológico, cultural y laboral. Además, señala que se pretende desarrollar en la comunidad estudiantil competencias y habilidades para actuar con base en los derechos humanos.

El plantel donde se realizó el trabajo de campo tiene implementado el BGC. La población estudiantil activa, una de las más numerosas entre las preparatorias del SEMS, es de 2,554 mujeres y 2,309 hombres. ${ }^{8}$ De acuerdo con personal del área de Orientación Educativa, se tiene registro de siete estudiantes embarazadas y 15 que son madres.

La preparatoria es miembro del Sistema Nacional de Bachilleratos (SNB) y se encuentra en el nivel 3. ${ }^{9}$ Esto implica que el plantel está integrando los requerimientos de la Reforma Integral de Educación Media Superior (RIEMS). ${ }^{10}$ Entre otras indicaciones, la escuela debe cumplir con las siguientes: que los planes y programas estén ajustados a la educación basada en competencias, que los docentes reúnan las competencias previstas por la RIEMS, que la vida escolar se organice para el proceso de aprendizaje, la seguridad y el desarrollo de los alumnos, y que las instalaciones sean suficientes para los procesos de aprendizaje y el desarrollo de competencias.

En el ciclo 2014-2015, el SEMS inició formalmente el Programa de Estudiantes con Discapacidad Auditiva. Sin embargo, desde 2012 el plantel prestaba sus aulas para que personas silentes pudieran cursar sus estudios de bachillerato. En este proyecto, que inició a cargo de padres de familia y de Educación Incluyente, A.C., hasta el ciclo 2015-A contaba con 24 estudiantes. Este panorama propicia condiciones para la existencia de relaciones cotidianas entre estudiantes no sordos y sordos.

Cuenta con convenios con diferentes instituciones, tales como el Instituto Mexicano del Seguro Social, el Consejo Estatal Contra las Adicciones de Jalisco, el Sistema para el Desarrollo

7 Aceves, W. (21 de marzo de 2015). Incrementa SEMS su matrícula en más de siete mil alumnos en el último año. Noticias Universidad de Guadalajara. http://www.udg.mx/es/noticia/incrementa-sems-su-matricula-en-mas-de-siete-mil-alumnos-en-el-ultimo-ano

8 Fuente: Segundo informe de trabajo 2014-2015. http://www.prepa7.sems.udg.mx/2do-informe-de-trabajo

9 Existen cuatro niveles para evaluar el cumplimiento de la incorporación de los requerimientos de la RIEMS, el nivel 1 es el de mayor categoría. 10 Esta reforma entró en vigor en el ciclo escolar 2009-2010, con el objetivo de solucionar los principales problemas de este nivel educativo: la baja cobertura, los índices de reprobación y deserción, los bajos niveles de rendimiento académico. La RIEMS precisó la creación del Sistema Nacional de Bachilleratos, con la intención de unificar los planes de estudios de este nivel educativo con la modalidad de educación basada en competencias. 
Integral de la Familia y con el Centro Universitario de Ciencias de la Salud. En conjunto con estas organizaciones se realizan diversas actividades, entre estas se encuentran revisiones médicas generales, registros para darse de alta al seguro social, vacunaciones, talleres para la prevención de adicciones, apoyo a alumnas embazadas y a alumnas madres (mediante becas, despensas y talleres), programa de paternidad y maternidad responsables (a través del cuidado virtual de bebés) y talleres sobre autoestima y descanso. Algunas de estas actividades son periódicas y otras son eventuales. La participación de las y los estudiantes está en función de la autorización de profesores, principalmente. ${ }^{11}$

Esta prepa, entre otros centros de educación media superior y superior de la UDG, ha llamado la atención de autoridades de la casa de estudios por motivos de inseguridad. Se han detectado casos de pandillas en las cercanías del plantel que buscarían realizar agresiones sexuales. En abril de 2016 se detectaron intentos y agresiones sexuales a alumnas en los trayectos y lugares cercanos a la escuela. ${ }^{12}$

\section{Subjetivación del sujeto de derechos sexuales}

Desde diferentes campos disciplinarios pueden encontrarse diversos planteamientos teóricos sobre qué es el sujeto, cómo se constituye y cuáles son las capacidades que tiene para actuar. Para Foucault (1988), hay dos significados para la palabra sujeto: uno se refiere al hecho de que un individuo es sometido a otro a través del control y la dependencia; el otro, a que se está atado a una propia identidad por la conciencia o el conocimiento de sí mismo. Para este autor, los sujetos se constituyen a través de la aplicación de técnicas de poder, de control y de dominación que "se ejercen sobre la vida cotidiana inmediata que clasifica a los individuos en categorías, los designa por su propia individualidad, los ata a su propia identidad, les impone una ley de verdad que deben reconocer y que otros deben reconocer con ellos." (1998: 7).

Así, los individuos viven procesos de sujeción que los configuran y los ubican en determinadas categorías históricas previas, tales como hombre, mujer o joven. Estos procesos se dan mediante la incorporación, reproducción y movilización de significados, prácticas (Scott, 1990) y relaciones sociales (Butler, 2007). De esta manera, los individuos perciben, hablan y actúan con base en lo que se considera propio o adecuado para cada categoría. En otras palabras, los sujetos se forman mediante definiciones culturales que configuran las formas de ser y que prevalecen a las construcciones propias (Amuchástegui y Rivas, 2005). Sin embargo, este posicionamiento pareciera describir y afirmar una idea determinista ya que los sujetos serían los efectos

11 Información recuperada mediante la revisión del Segundo informe de trabajo 2014-2015 y entrevistas informales con personal del área de Orientación Educativa.

12 Saavedra, V. (11 de abril de 2016). Estudiantes de la UdeG han sido víctimas de intentos de agresiones sexuales. El Occidental. http://www. oem.com.mx/eloccidental/notas/n4131709.htm Adicionalmente, estudiantes entrevistadas mencionaron que ellas mismas o compañeras vivieron intentos de agresión sexual o de secuestro.

Diólopos 
de diversos discursos y, por lo tanto, su mera reproducción (Amuchástegui y Rivas, 2005). Ahora bien, cabría preguntarse, una vez que inician estos procesos de sujeción, ¿los sujetos están destinados a reproducir estas categorías y las formas "normales" de asumirlas? ¿los sujetos tienen capacidad de agencia?

El mismo Foucault (1999) propone hablar de prácticas de liberación y prácticas de libertad. Las primeras son parte de una oposición a los poderes que someten o imponen ciertos modos de ser, es decir, se refieren a los intentos de liberarse de algo o alguien. Las segundas, las prácticas de libertad, tienen un hilo conductor que es el cuidado de sí y de los demás, y se refieren a las acciones creativas de los individuos para eliminar o disminuir las relaciones de poder. Las prácticas de liberación son una condición política e histórica para las prácticas de libertad.

Considerando lo anterior, para el presente trabajo se entiende que los sujetos se constituyen "dentro de los límites de la trama de relaciones sociales y de poder pero con potencial para la autonomía" (Rivas, 2004b).

Entonces, antes de hablar de la posibilidad de la existencia y del devenir sujeto de derechos sexuales, es importante tener en cuenta que los individuos han tenido procesos de sujeciones previos, ¿a qué y de qué manera se ha sujetado?

A continuación se presentan los elementos teóricos que ayudan a responder la cuestión antes planteada. En primer lugar, se revisan los conceptos y las relaciones entre juventud, sexualidad y género. Posteriormente, se define qué se entiende por sujeto de derechos sexuales. Por último, se describe el proceso de formación a través de la educación formal y el de subjetivación.

\section{Juventud, sexualidad y género}

Ser joven es un acto discursivo de nombrarse o ser nombrado (Serrano, 2002). Este acto tiene implicaciones muy complejas. Supone modos de organizar las biografías individuales, pautas de interacción y de socialización, estilos de vida, tipos de distribución de los recursos materiales y simbólicos con los cuales las sociedades se organizan y determinan el poder que las sustenta, entre otros aspectos (Serrano, 2002). Ser joven se constituye en una forma de narrar los cursos vitales con base en la relación de los tiempos y espacios sociales y subjetivos (Villa, 2007).

La categoría joven genera imágenes diversas de lo que representa ser joven. De los atributos que deben tener estas personas, en cuanto comportamientos, aspiraciones, forma de vestir, entre otros. Estos no siempre son compatibles y con frecuencia tratan de imponerse unos a otros (Feixa, 1995, en Juárez, 2009). En este sentido, existen concepciones hegemónicas sobre lo que significa ser joven, que producen un eje de diferenciación y estereotipos que configuran las prácticas y las relaciones sociales.

Dentro de las concepciones hegemónicas, se encuentran las que consideran a la población joven como una etapa de desarrollo psicobiológico, como problema de desarrollo y como dato demográfico. En estas, la relación entre sexualidad y juventud es problemática. 
Como etapa de desarrollo psicobiológico. En esta perspectiva, la juventud es considerada como un fenómeno universal que se caracteriza por una serie de cambios físicos y psicológicos. Es una etapa de transición de la infancia a la adultez normal, por lo tanto, son personas inmaduras incapaces de razonar sus acciones; de allí que ciertos aspectos, como la sexualidad, reciban especial vigilancia por parte de los adultos (Bonder, 1999, en Alpízar y Bernal, 2003; Villa, 2007). En relación con la sexualidad, esta se entiende como algo negativo pues su ejercicio se vincula con embarazos o ETS (Villa, 2007). Así, desde esta concepción, tanto la juventud como la sexualidad son problemáticas y, más aún, la relación entre ambas.

Como problema de desarrollo. Esta concepción está muy vinculada con la primera. Debido a que la población joven es inmadura y vulnerable, es muy fácil que acceda a consumir drogas o tener prácticas sexuales irresponsables. Este tipo de vulnerabilidades traen consecuencias como adicciones, embarazos no deseados o enfermedades e infecciones de trasmisión sexual (Ferratori, 1981, en Alpízar y Bernal, 2003).

En término generales, estas concepciones indican que las y los jóvenes no están lo suficientemente preparados (o maduros) para razonar, e incluso para realizar prácticas sexuales o para afrontar las situaciones que podrían derivar de estas (tales como las enfermedades de trasmisión sexual o los embarazos). Por tal razón, desde la visión de los adultos, es necesario vigilar o posponer el ejercicio de la sexualidad hasta que se logre una determinada madurez física y emocional (Villa, 2007). Así, estas concepciones configuran determinadas relaciones entre adultos y jóvenes.

En relación con este último punto, es importante destacar que en las relaciones entre jóvenes y adultos existe una cuestión generacional. De acuerdo con Villa (2007), las generaciones son nociones históricas con una estructura biográfica y social de las edades. Una generación es un modo particular de estar con otros, en el que confluyen simultáneamente un estar en el tiempo, condiciones biográficas y un modo de relación con la cultura (Villa, 2007). En cada generación existen pautas sociales y culturales, lo que genera que en las relaciones intergeneracionales se realicen intercambios bidireccionales de conocimientos, valores, actitudes y pautas de comportamientos; sin embargo, en la generación más antigua existe una responsabilidad de guiar y enseñar.

En resumen, el acto de nombrarse joven, las imágenes culturales relativas a la juventud y las relaciones sociales que se generan entre jóvenes y adultos configuran, entre los individuos llamados jóvenes, una peculiar forma de percibir, pensar, sentir y actuar, es decir, la formación de una determinada subjetividad.

Si bien la sexualidad y el género se vinculan y entrelazan en la teoría y en la vida cotidiana, estas deben considerarse como dos categorías independientes.

La sexualidad es una dimensión de la vida del ser humano (Amuchástegui y Rivas, 2004), que hace referencia a las posibilidades del cuerpo en relación con los deseos, placeres, prácticas, 
relaciones y fantasías (Amuchástegui y Rivas, 2005). En el ejercicio de la sexualidad intervienen significados, tradiciones, valores, identidades y relaciones de poder (Weeks, 2015, en prensa).

La sexualidad es configurada por fuerzas sociales y es

el resultado de distintas prácticas sociales que dan significado a las actividades humanas, de definiciones sociales y autodefiniciones, de luchas entre quienes tienen el poder para definir y reglamentar contra quienes se resisten. La sexualidad no es un hecho dado, es un producto de negociación, lucha y acción humanas (Weeks, 1998: 30).

Cada contexto social concreto configura los deseos, las relaciones y las prácticas (Weeks, 1998) relativas a la sexualidad. En el caso de las sociedades occidentales cristianas —entre las cuales se encuentra México-, los aspectos sexuales son un terreno de angustia y conflicto moral; de allí que exista tanto un rechazo como una preocupación hacia el cuerpo y a lo sexual. Estas premisas están estrechamente ligadas con la moralidad y las concepciones impuestas por la religión cristiana. En otras palabras, la sexualidad es una dimensión vigilada y los hechos vinculados a esta son considerados como hechos naturales (Weeks, 1998).

Así, la cotidianidad de estas sociedades está organizada por un orden, el cual pareciera ser natural e inmutable (Amorín, 2007). En estos contextos, las personas en la vida diaria expresan significados compartidos (Ramos y Vásquez, 2005) y socializan de tal manera que las relaciones y jerarquías entre hombres y mujeres y las prácticas sociales se perciben como naturales e incuestionables (Ruiz, 2000, en Ramos y Vásquez, 2005) y que, por el bien de la sociedad, no deben cambiar ni modificarse.

Este orden social y sexual se interioriza y se reproduce a través de normas y argumentos esencialistas. De acuerdo con Weeks (1998), estas normas tienen una multiplicidad de aspectos, en cuanto formales e informales, legales y extralegales, pero que delimitan las formas aceptadas y normales de sentir, pensar y comportarse.

Estas normas y argumentos esencialistas integran un orden simbólico que se articula con las condiciones materiales de cada sociedad. No se afirma que estas normas sean aceptadas por la totalidad de la sociedad pero sí por la mayoría de la población, debido a la historia que ha tenido la moralidad católica en el país (Amuchástegui y Rivas, 2004). A continuación, se puntualizan tres normas y sus argumentos esencialistas que representan limitaciones para la subjetivación del sujeto de derechos sexuales.

- La finalidad de la sexualidad es la reproducción. De acuerdo con Granados (2002), el orden sexual está escindido del placer y subordinado a la reproducción biológica. Entonces, las relaciones sexuales se basan en la genitalidad y son para fines reproductivos (Amuchástegui y Rivas, 2005), de tal manera que otras manifestaciones de lo sexual 
deberían evitarse. De acuerdo con Amuchástegui (2001), el posicionamiento subjetivo de los hombres, de considerar la reproducción como un incómodo imprevisto de la actividad sexual, limita las posibilidades de constituirse a sí mismos como sujetos de derechos sexuales.

- La mujer y su autonomía corporal. Culturalmente, el placer erótico está subordinado a la procreación, e incluso en algunos casos el placer erótico es negado, principalmente a las mujeres (Amuchástegui y Rivas, 2008).

- Posibilidades diferenciadas para sentir placer. La estructura social prescribe una serie de funciones para hombres y mujeres como propias o naturales de sus respectivos sexos (Bustos, 1994, en Lartigue, 1996). En lo que respecta a la sexualidad, existen atributos diferentes para hombres y mujeres, lo cual determina las posibilidades de sentir placer. Asexualización de lo femenino (el cuerpo es objeto de sujeción, disponible al deseo masculino, rol pasivo en la relación sexual, posibilidad limitada de placer). Privilegios sobrevalorados de la masculinidad (dominio, rol activo en la relación sexual, libertad para relaciones sexuales prematrimoniales y extramatrimoniales, falsa exigencia de celibato antes del matrimonio, estímulo para adquirir experiencia sexual previa, derecho conyugal de satisfacer el deseo cuando se requiera).

La sexualidad está matizada por distintas condiciones, tales como la clase, el grupo étnico, la edad, la orientación y preferencia sexual y la religión (Vance, 1984). En el caso de las y los jóvenes, la sexualidad recibe una atención social muy especial. De acuerdo con Foucault (1998), la sexualidad opera como un dispositivo, debido a que hace posible proliferar, innovar, anexar, inventar y penetrar los cuerpos de manera cada vez más detallada. Este dispositivo se implementa en las relaciones de poder que se gestan entre hombres y mujeres, viejos y jóvenes, maestros y alumnos. De esta manera, padres (la familia), maestros y adultos son los principales agentes de este dispositivo, pues tienen que "enseñar" "guiar" a las y los jóvenes. La sexualidad de los jóvenes se cuestiona y vigila pues ellos están en peligro y son peligrosos (Foucault, 1998).

La normatividad y los argumentos esencialistas antes mencionados están íntimamente ligados con los modelos hegemónicos de masculinidad y feminidad. El eje principal mediante el cual se organiza la sexualidad es el género (Connell, 2002).

Género se entiende como un sistema simbólico que se ha construido históricamente, que asigna posiciones jerárquicas a cada individuo, en cuanto hombre o mujer, y que regula y configura las relaciones y las prácticas (Scott, 1990). Las relaciones entre hombres y mujeres y sus prácticas no son una mera expresión de lo biológico ni una dicotomía fija en la vida humana. Todas las relaciones y prácticas sociales incluyen interpretaciones. Es decir, hablar de hombre o mujer va mucho más allá de una enunciación nominativa, remite a un sistema de interpretaciones y referencias que han sido acumuladas a través de la historia (Connell, 2002). 
El género, como dimensión que delimita las prácticas y las relaciones, se considera como un orden social. De acuerdo con Connell (2002), los diferentes hechos que evidencian una diferencia entre hombres y mujeres están conectados y forman un patrón, al cual se le denomina orden de género. Culturalmente, estos patrones son concebidos como normales o naturales. Son mantenidos o reforzados continuamente en las relaciones sociales cotidianas. De tal manera que es mediante las prácticas y las relaciones diarias que se contribuye a mantener o diseminar las diferencias y las inequidades entre hombres y mujeres. Incluso, estas prácticas "normales" se aceptan y se reproducen de "buena gana" (Connell, 2002).

El orden de género también se caracteriza por producir y configurar las formas ideales de masculinidad o feminidad. Aunque hay manifestaciones y posibilidades en cada contexto concreto, existen significados compartidos asociados a lo masculino y a lo femenino que forman un modelo hegemónico de masculinidad y feminidad. Este modelo representa una fuerte barrera para el ejercicio y disfrute de los DDSS (López y Güida, 2002).

Según este modelo hegemónico, la masculinidad y la feminidad implican características de personalidad específicas. La masculinidad hegemónica tiene atributos como la fuerza, el coraje, el riesgo, la seguridad, la independencia, la baja expresión de emociones, la realización de actividades lógicas o que impliquen destreza física (Mantilla, 1996). La feminidad se caracteriza por la debilidad, la sutileza, la expresión de afecto, el cuidado de los otros, la dependencia afectiva y económica, la delicadeza, entre otras (Mantilla, 1996).

En relación con las prácticas sexuales, el modelo hegemónico configura los comportamientos "aceptados". En el caso de la masculinidad, se construyen hombres activos en la búsqueda del placer sexual y "descentrado" de las decisiones reproductivas. Es una masculinidad que renuncia a lo femenino, que aprueba la homofobia y sostiene el sexismo y el heterosexismo (López y Güida, 2002). En el caso de la feminidad, las mujeres se centran en sus roles y funciones reproductivas, postergando la búsqueda del placer sexual (López y Güida, 2002).

En resumen, los individuos tienen procesos de sujeción a la juventud, a la sexualidad y al género. Estos procesos están sustentados en imágenes que indican que existen formas normales y naturales de comportarse, de relacionarse y de ser (ya sea joven, hombre, mujer). Estas imágenes fomentan significados, relaciones y prácticas inequitativas y posiciones jerarquizadas. Descritos así, los procesos de sujeción representan barreras para la subjetivación del sujeto de derechos sexuales.

\section{Sujeto de derechos sexuales y subjetivación}

Desde una perspectiva educativa, el sujeto de derechos se entiende como la noción del derecho a tener derechos (Magendzo, 2001; Sonderéguer, 2012). De esta manera, los derechos están en el sujeto, se practican, se viven. Es decir, tiene un papel activo y creativo en relación con sus derechos y con la sociedad. 
Pero, para el caso de los derechos sexuales y de jóvenes ¿es suficiente solo hablar de esta noción del sentido a tener derechos? Con base en lo que se describió previamente, el sujeto de derechos sexuales debe desarrollar un tipo de subjetividad que incorpore la noción de tener derechos (Magendzo, 2001; Sonderéguer, 2012; Petchesky y Judd, 2006; Amuchástegui y Rivas, 2005), una conciencia que cuestione las imágenes culturales hegemónicas relativas al "ser joven", de la sexualidad y del género (Cabral, 2008 y Miyares, 2003) y una apropiación del cuerpo (Amuchástegui y Rivas, 2004).

Este tipo de subjetividad al que se hace referencia puede derivar en varias posibilidades; sin embargo, para el caso de los derechos sexuales es necesario un hilo conductor que guíe estos aspectos: la ética. Los DDSS tienen una base ética que se articula en cuatro principios: integridad corporal, autonomía, igualdad y respeto a la diversidad (Correa y Petchesky, 2001). En este sentido, también se incluyen los valores sexuales: la desculpabilización, responsabilización y el consentimiento (Lamas, 2016).

Ahora, en relación con la subjetivación del sujeto de derechos sexuales ¿de qué manera se da este proceso? Desde la educación en derechos humanos se afirma que el sujeto de derechos se forma mediante los procesos educativos (Magendzo, 2001); sin embargo, el devenir sujeto de derechos sexuales sería un proceso complejo que involucra múltiples ámbitos y elementos, es decir, excede a lo meramente educativo. Se asume que la educación formal funge como catalizador para dicha subjetivación debido a que el ámbito educativo es uno de los principales espacios donde se ha integrado el discurso de los derechos sexuales. Considerando lo anterior, es relevante establecer una distinción en el uso de los términos subjetivación y formación. Se describirá cada uno de ellos iniciando por la formación.

\section{Formación del sujeto de derechos sexuales}

Para la formación del sujeto de derechos sexuales, se estaría hablando concretamente de un tipo de educación que contribuya al desarrollo de los siguientes aspectos: 1) el sentido de tener derechos sexuales; 2) conciencia crítica para problematizar las normas y las relaciones tradicionales de la sexualidad y del género que originan inequidad y violencia; y 3) la apropiación subjetiva del cuerpo propio. Estos tres aspectos deberían ser desarrollados con una guía ética, para visualizar y crear maneras más justas de relacionarse y de luchar por el reconocimiento de derechos con base en la dignidad humana. Para que la educación formal logre contribuir a la subjetivación del sujeto de derechos sexuales es necesaria una alineación entre los diferentes elementos del currículo. Pero ¿por qué se elige en primer momento al currículo? ¿a qué se refiere con esta alineación?

Se considera que los derechos humanos se aprenden y se enseñan de diferentes maneras. En relación con lo primero, se incluyen los deseos, intereses, motivaciones, compromisos y condiciones concretas que las y los estudiantes poseen y experimentan en sus cursos y momentos 
vitales. En cuanto a lo segundo, se involucran los conocimientos, habilidades, creencias, valores y formas de entender la educación y las formas de enseñar de las y los docentes. A pesar de lo anterior, se considera que el rol del currículo oficial configura las posibilidades y es fundamental en la constitución del sujeto de derechos sexuales.

De acuerdo con Magendzo y Toledo (2009), el currículo tiene una estrecha relación con el poder y con la negociación de saberes. Por una parte, estos autores precisan que el currículo escolar, además de ser un acto técnico-pedagógico, es uno político pues en su diseño se define el proceso de seleccionar y jerarquizar contenidos. En otras palabras, en él se involucran intereses, tendencias, historias y posiciones ideológicas y pedagógicas. Por otra parte, en el currículo escolar oficial se genera un proceso de negociación entre diversos saberes y agentes. En su diseño participan especialistas de las disciplinas académicas, especialistas en currículos y profesores, empresarios, padres y madres de familia, miembros de la comunidad y de iglesias, además de agentes y agencias internacionales de financiamiento. Cada actor y organización aporta una concepción de educación, sus intereses y sus visiones, de tal manera que en este converge una heterogeneidad de percepciones y valores (Magendzo y Toledo, 2009).

Se parte de que el currículo oficial es sumamente importante ya que

establece los límites y controles, posibilidades y opciones del proceso formativo de los estudiantes. En otras palabras, el currículum oficial es la "carta de navegación" o columna vertebral constituida por elementos básicos, cuya selección, organización y relación tienen implicancias en las prácticas docentes (Magendzo y Toledo, 2009: 40).

En términos concretos, se podría decir que el currículo oficial se entiende como "un ordenamiento u organización y relación entre los objetivos y contenidos, o sea, los conocimientos, habilidades, destrezas, actitudes y valores que se espera que los estudiantes logren en los distintos niveles de formación." (Magendzo y Toledo, 2009: 140).

Considerando lo anterior, se entiende que para la formación de sujetos de derechos sexuales es preciso que exista una congruencia y una alineación entre los diferentes elementos que integran el currículo oficial. En un primer momento, que se precise el objetivo explícito de formar sujetos de derechos sexuales. Enseguida, deben integrarse ejes trasversales y asignaturas sobre sexualidad y ciudadanía que se vinculen entre sí. Los contenidos debieran considerar:

- Antecedentes históricos de los DDHH y de los DDSS. Para desarrollar una memoria y una conciencia histórica al "nunca más" (Magendzo y Toledo, 2009). Para que las y los jóvenes, ubicados en un momento histórico particular, puedan conocer y valorar las diferentes razones históricas por las que ciertos grupos de personas (mujeres, homosexuales, 
lesbianas, jóvenes, pobres) han sido amenazados o violentados en sus derechos de manera cotidiana, institucionalizada y sistemática (Morgade, 2006).

- Precisar qué y cuáles son los DDHH y los DDSS. Para poseer un conocimiento básico sobre cuáles son los derechos que se poseen. Para ayudar a desarrollar el sentido de tener derechos.

- Información científica y libre de prejuicios sobre sexualidad (por ejemplo, métodos de anticoncepción y de prevención de infecciones de trasmisión sexual). Para poder tomar decisiones sanas, seguras y responsables sobre el ejercicio de la sexualidad.

- Identidad, roles y relaciones de género. Para dar cuenta de cómo los individuos se forman y visualizar las relaciones injustas e incluso violentas que establecen y reproducen. Es decir, estos contenidos son útiles para ayudar a desarrollar la conciencia crítica de género.

Las habilidades, actitudes y valores que se debieran desarrollar y promover, están en concordancia con las características que posee el sujeto de derechos sexuales, entre ellas: la argumentación, el lenguaje de crítica y el lenguaje de posibilidad, la integridad corporal, autonomía, igualdad, y respeto y aceptación de la diversidad sexual.

En resumen, los procesos educativos tienen un rol catalizador en la subjetivación del sujeto de derechos sexuales. Si bien es cierto que los docentes realizan acciones para contribuir al proceso de subjetivación y que las y los estudiantes pueden tener intereses y son capaces de generarse compromisos en cuanto a los derechos sexuales, el currículo oficial configura el hacer de los primeros, así como los conocimientos, habilidades, actitudes y valores que deben desarrollar los segundos, por lo que adquiere una importancia básica y es punto de partida para las posibilidades de las y los jóvenes para devenir sujetos de derechos sexuales dentro de contextos educativos.

\section{Subjetivación del sujeto de derechos sexuales}

Antes de describir este proceso, es relevante puntualizar algunas ideas fundamentales que hasta aquí se han desarrollado: 1) la subjetivación se define como el proceso de sujeción a "algo"y que los procesos de subjetivación son configurados, pero no determinados, por los significados, prácticas (Scott, 1990) y relaciones sociales (Butler, 2007) que producen y reproducen la vida social cotidiana; 2) Se entiende que los individuos viven procesos de sujeción históricamente elaborados, pero que están en trasformación (para el interés de este trabajo, al "ser joven", la sexualidad y al género) que pueden representar barreras para la subjetivación del sujeto de derechos sexuales; 3) Según la definición y caracterización del sujeto de derechos sexuales, este tiene la cualidad de una determinada subjetividad que incorpore la noción de tener derechos, 
una conciencia que cuestione las imágenes culturales hegemónicas relativas al "ser joven", de la sexualidad y del género, y una apropiación del cuerpo.

Ahora bien, ¿de qué manera se pueden contrarrestar las sujeciones previamente descritas? ¿de qué manera es posible la subjetivación del sujeto de derechos sexuales? ¿qué tipo de significados se tienen que movilizar, construir o deconstruir? ¿qué tipo de prácticas se tienen que realizar? ¿qué tipo de relaciones se tienen que establecer?

Con base en lo anteriormente expuesto, y con argumentos de la educación en derechos humanos y teorías feministas que se han plasmado a lo largo del artículo, se deben considerar los siguientes aspectos para dar cuenta del proceso de subjetivación en jóvenes estudiantes como sujetos de derechos sexuales:

- Los significados atribuidos a las imágenes culturalmente aceptadas sobre "ser joven", "ser hombre", "ser mujer" en relación con la sexualidad. Los posicionamientos subjetivos ante las normas hegemónicas de juventud, sexualidad y género.

- Los tipos de prácticas (sexuales) que se oponen a las normas hegemónicas e imágenes culturales. En otras palabras, las prácticas éticas que permitan el cuidado de sí mismo y de los demás. Lamas (2016) afirma que las prácticas sexuales deben estar pautadas por la desculpabilización, la responsabilización y el consentimiento (Lamas, 2016).

- La manera como se establecen las relaciones sociales entre los sexos y entre generaciones. En este sentido, Correa y Petchesky (2001) afirman que las relaciones deben estar guiadas por cuatro principios éticos: la integridad corporal, la autonomía, la igualdad y el respeto a la diversidad.

Por último, según los planteamientos aquí expuestos, un posible antagonismo entre las sujeciones descritas y la subjetivación del sujeto de derechos sexuales, y las condiciones espaciales y temporales de las y los jóvenes, se podrían anticipar algunos escenarios muy interesantes. Uno de ellos es la visualización del sujeto de derechos sexuales.

Las propuestas de Bauman (2002) y Touraine (2006) brindan una explicación a este escenario. Por un lado, Bauman (2002) refiere que el momento histórico que se vive actualmente podría describirse mediante la metáfora de "liquidez" o "fluidez". Esta propuesta intenta aprehender la naturaleza del momento actual de la modernidad. Con el concepto de liquidez, el autor trata de dar cuenta de la transitoriedad y precariedad de los vínculos humanos dentro de una sociedad individualista y poscapitalista. Esta llamada modernidad líquida está descrita como un tiempo imprevisible, sin certezas y siempre cambiante. Por otro lado, Touraine (2006) habla de los tiempos modernos como una etapa en la cual el ser social se convierte en individuo, en un ser aislado. Un individuo que entiende y actúa porque cree ser libre al satisfacer necesidades crea- 
das por el capitalismo, tales como el consumo irracional. Vive en una libertad disfrazada y que engaña. Es un ser consumidor más que un creador de experiencias.

En lo que respecta a la sexualidad, Amuchástegui y Rivas (2004) precisan que los tiempos contemporáneos ofrecen una multiplicidad de discursos sobre los usos del cuerpo y los placeres, que favorecen el surgimiento de zonas de tensión donde la resistencia y lo creativo pueden emerger.

Así pues, la llamada modernidad líquida, caracterizada por la precariedad e incertidumbre, genera las condiciones que hacen posible la formación de sociedades y de sujetos híbridos. Las primeras se caracterizan por la coexistencia y la disputa de discursos y argumentos; los segundos se ven limitados a mantener relaciones y compromisos de manera efímera y a que su capacidad reflexiva y acción (ética) se vea obstaculizada. Por lo tanto, se considera que los sujetos de derechos sexuales se harán visibles en momentos y espacios concretos, por ejemplo, cuando la dignidad propia o la de alguien más esté siendo violentada, cuando los intereses o compromisos políticos tengan que afirmarse, cuando se cuestione y critique una norma. En otras palabras, la subjetivación del sujeto de derechos sexuales no es fija o inamovible, sino que es dinámica, se hace visible, se desvanece y vuelve a ser visible.

\section{Metodología}

La investigación tuvo el objetivo general de describir de qué manera las y los jóvenes, estudiantes de una institución que tenga como propósito la formación de sujetos de derechos, devienen sujetos de derechos sexuales. Para este artículo se presenta lo relativo a los siguientes objetivos específicos: 1) describir los significados que las y los estudiantes atribuyen a la sexualidad y al "ser joven" en su relación con el ejercicio de esta; 2) identificar los elementos curriculares que están enfocados a formar el sujeto de derechos sexuales.

El primer objetivo particular se enfoca en los significados, por lo tanto, se pretende estudiar la subjetividad de las y los jóvenes estudiantes en una dimensión constitutiva. El segundo objetivo deriva del importante papel que se atribuye a la educación formal en la subjetivación de sujetos de derechos sexuales.

Estudiar la subjetividad nos permite reconocer y enfocar las maneras en que los individuos extraen sentido de sus propias experiencias, en un marco de referencia de sus concepciones, motivaciones, sentimientos e intereses, incluyendo sus entendimientos, conscientes e inconscientes, y las formas culturales disponibles, a través de las cuales esos entendimientos son constreñidos o estimulados (McLaren, 1997). La subjetividad, entendida como proceso y dinámica, se configura por los distintos órdenes sociales y se mantiene o reconfigura en la interacción con otros, en la cotidianidad.

Tomando en cuenta lo anterior, el objeto de estudio y los objetivos de investigación planteados, la presente investigación corresponde a un estudio con un enfoque metodológico cua- 
litativo. Esta perspectiva es la adecuada si se pretende comprender a las personas y la acción social, además, permite estudiar la subjetividad, las vivencias y localizar las potencialidades hacia una trasformación (Taylor y Bogdan, 1994; Ragin, 2007a; Strauss y Corbin, 2002; Packer, 2013; Tarrés, 2004). En el caso particular de la sexualidad, Villaseñor (2008) indica que una perspectiva cualitativa es pertinente para comprender adecuadamente las ideas y las vivencias sobre sexualidad de las y los jóvenes.

El presente estudio se interesó en una población en particular (jóvenes estudiantes), en un proceso en específico (subjetivación del sujeto de derechos sexuales) y en un contexto educativo concreto (Preparatoria del SEMS de la UDG). Esta institución tiene como uno de sus objetivos formar sujetos de derechos. En este sentido, esta investigación corresponde a un estudio de caso, ya que este método es pertinente para un proceso que pretende comprender un programa educativo o una población en particular (Stake, 2007; Rodríguez, Gil y García, 1996; Galeano, 2012).

Se utilizaron dos técnicas para la recolección de información: la entrevista semiestructurada y la revisión documental.

\section{Entrevista semiestructurada}

El lenguaje contribuye a construir determinada subjetividad y es la forma de acceder a esta. De acuerdo con McLaren (1997), el lenguaje y la subjetividad informan sobre nuestra conciencia práctica, en la cual el yo depende siempre de un nosotros, es siempre contingente con respecto a la localización histórica y social y al conjunto de relaciones sociales que construyen la totalidad social más amplia. De allí que se consideró pertinente el uso de la entrevista.

La entrevista permite recabar determinada información para comprender ciertos aspectos de la vida cotidiana de las personas en sus propios términos y desde su propia voz (Packer, 2013; Taylor y Bogdan, 1994; Ragin, 2007a; Strauss y Corbin, 2002; Kvale, 2011). Con esta técnica es posible obtener descripciones del mundo vivido de los entrevistados con respecto a la interpretación del significado de los fenómenos. La entrevista es similar a una conversación cotidiana, aunque se realiza con un propósito y de una manera específica (Kvale, 2011).

El diseño de la entrevista fue de carácter temático. Se favoreció la fluidez de una conversación, pero también se guio el rumbo de la entrevista hacia los temas de interés de la investigación, el cual fue identificar los significados atribuidos a la sexualidad y a "ser joven" en su relación con esta para dar cuenta, en parte, de la subjetivación del sujeto de derechos sexuales en jóvenes.

\section{Revisión documental}

Más arriba se precisó la relevancia de los documentos oficiales en los procesos de enseñanzaaprendizaje de los derechos humanos. Magendzo y Toledo (2009) precisan que el currículo oficial 
establece los límites y controles, posibilidades y opciones del proceso formativo de los estudiantes. En otras palabras, el currículum oficial es la "carta de navegación" o columna vertebral constituida por elementos básicos, cuya selección, organización y relación tienen implicancias en las prácticas docentes (Magendzo y Toledo, 2009: 40).

Considerando lo anterior, y el rol que se atribuye a la educación formal, se revisaron diversos documentos oficiales del BGC de la UDG con el objetivo de identificar elementos del currículo oficial que pueden contribuir a la formación del sujeto de derechos sexuales. Para cumplir con este objetivo se siguieron algunas de las actividades que propone Quintana (2006):

1) Rastreo, inventario y clasificación de los documentos existentes y disponibles.

2) Selección de los documentos más pertinentes para los propósitos de la investigación.

3) Leer a profundidad el contenido de los documentos seleccionados.

4) Identificar los elementos definidos en las categorías apriorísticas.

\section{Significados atribuidos a la sexualidad}

Al tener como propósito comprender las posibilidades del devenir de un sujeto de derechos sexuales, fue pertinente identificar los significados atribuidos a la sexualidad. Por tal motivo, una de las principales cuestiones fue pedir a las y los participantes que la definieran y asociaran palabras con ella. Los hallazgos indican significados que se adscriben a los discursos religiosos, hegemónico sexual y de sexualidad integral.

Asumir que la sexualidad es o está subordinada a la reproducción, es una de las principales normas sociales y argumentos tradicionales que impiden el disfrute de los derechos sexuales. Solo una participante refirió que la sexualidad es "... como reproducción, eh... pues si... (risas).... Tener... contacto hombre y mujer... y ahí sale reproducir vida... es lo más lógico, ¿no?" (Dana, 17 años). Este posicionamiento se adscribe al discurso religioso sobre la sexualidad, el cual indica que las mujeres y los hombres heterosexuales - como única posibilidad-deben tener relaciones sexuales únicamente para crear vida y, por lo tanto, el placer, principalmente de las mujeres, se oculta y se ignora.

Cuando la sexualidad está subordinada a las funciones reproductivas, las posibilidades de experimentar placer se limitan. Por lo tanto, este significado otorgado a la sexualidad representa una limitante para la subjetivación del sujeto de derechos sexuales.

En la mayoría de las respuestas, la sexualidad se relacionó con el sexo biológico y el coito. Es decir, los siguientes significados se adscriben al modelo sexual hegemónico:

Manuel (17 años). Yo sexualidad lo relaciono con género... o sea las cosas que definen a los hombres y las mujeres. 
Víctor (16 años). Género sexual, hombre o mujer... pues el coito, relaciones sexuales... esas dos palabras.

Karla (17 años). Sexualidad, el cuerpo humano... desnudo... no sé y ya. O sea lo asocio con el sexo, hombre, mujer.

Heidi (18 años). Sexualidad es todo ¿no?, es si eres hombre, si eres mujer, sexualidad también como lo veo yo pues es tener relaciones sexuales, mmm... ¿qué más? En sí es eso, el género y tener relaciones sexuales.

En relación con las definiciones anteriores, se identificaron dos aspectos relevantes. Por una parte, se puede distinguir que los significados atribuidos a la sexualidad derivan de la configuración histórica de la sexualidad como dispositivo de control social que se legitimó desde diversos campos discursivos, principalmente desde la biología, la medicina y la psiquiatría. La sexualidad, desde la visión biologicista, establece una dicotomía hombre/mujer en función de las características físicas. En esta perspectiva, de acuerdo con Morgade (2006), se recrea un discurso de "lo natural", en el cual se clasifican las trasgresiones morales diferentes a la norma heterosexual, como otras identidades y orientaciones sexuales.

Por otra parte, concebir la sexualidad como equivalente a las relaciones sexuales, pareciera estar vinculado con las experiencias e inquietudes de las y los jóvenes. Checa (2003) precisa que, de acuerdo con varias investigaciones, en la adolescencia la sexualidad se potencia a partir de nuevas experiencias sexuales y de una fuerte erotización, que se canalizan en las relaciones sexuales.

Respecto a los significados donde se vinculó la sexualidad con el sexo biológico y las relaciones sexuales heterosexuales, se refleja la existencia de un discurso heteronormativo socialmente arraigado. Es decir, el significado atribuido a la sexualidad está configurado por un sistema binario jerárquico masculino/femenino y por la heterosexualidad obligatoria. De esta manera, estos significados podrían conducir a la discriminación e inferiorización, tanto de otras orientaciones sexuales diferentes a la heterosexualidad como de cualquier otra identidad diferente a la dicotomía hombre/mujer. Los hallazgos referentes a la discriminación hacia otras preferencias sexuales se presentarán en el apartado de valores sexuales; lo referente a otras identidades no se abordó en el trabajo.

En cuanto a los significados emergentes, aunque se mantienen nociones de sexo biológico y relaciones sexuales, estos se caracterizaron por la hibridación con otros discursos de la sexualidad. Se asocia a la sexualidad con las formas de ser y de desear y con contenidos afectivos y relacionales, tal como lo muestran las siguientes participaciones:

Valeria (18 años). Yo siento que más bien es como la forma de pensar de cada quien. Porque, por ejemplo, sexualidad y sexo son cosas muy diferentes. Por ejemplo, sexo es como el acto de 
hacer la relación sexual, y la sexualidad, y más bien como... o sea, como la forma de pensar de cada quien, como las preferencias sexuales, algo así.

Alejandro (17 años). Se me viene a la mente, como hombre y mujer, relaciones sexuales, hasta una amistad.

Si en las respuestas relacionadas con la perspectiva biologicista se reafirma la heterosexualidad obligatoria, en los fragmentos que se acaban de presentar se abren las posibilidades para otras orientaciones sexuales y la afectividad. Se identifican elementos que pertenecen a una conceptualización más amplia e integral de sexualidad, en la cual se incluyen el sexo, el erotismo, la orientación sexual y la efectividad. Este tipo de definiciones provienen de las concepciones propuestas por diversas organizaciones civiles y convenciones sobre los derechos humanos y derechos sexuales.

En algunos significados atribuidos a la sexualidad se pueden identificar la intersección e hibridación de diversos discursos y la forma como se negocian. Lo anterior se pudo evidenciar en lo que mencionó Patricia:

Patricia (17 años). Pues todo... pues porque a mí me han enseñado que la sexualidad está en tu forma de vida, en lo que haces. Pues esto que te digo es porque me lo enseñaron, pero cuando escucho sexualidad, pues pienso en el sexo, en el acto sexual o cuando tienes relaciones o cuando tienes una pareja y la quieres mucho, en el erotismo.

Particularmente, en lo que refiere Patricia se encuentran elementos adscritos a la heternormatividad previamente mencionada y otros vinculados a la perspectiva de la sexualidad integral. Ella hace referencia a lo que le han enseñando y lo que cree sobre lo que es sexualidad, lo que hace evidente una hibridación y negociación entre saberes.

\section{Significados atribuidos a "ser joven"}

Explorar este aspecto es relevante para conocer las barreras que la población del estudio tiene para constituirse como sujetos de derechos sexuales en función de la etapa que viven. Es importante precisar que teóricamente se ubicó a las y los participantes en la categoría joven, pero no todos se situaron dentro de esta, sino que apareció otra: la adolescencia.

Así que, antes de presentar los resultados correspondientes a esta categoría, es necesario realizar una precisión en cuanto al uso de las categorías adolescencia y juventud. El uso de uno u otro término se debe a la ciencia en la que está posicionado el investigador. La adolescencia es un término utilizado en la psicología evolutiva para dar cuenta de los procesos y trasformaciones que tiene un individuo. El término juventud, utilizado en ciencias sociales, se centra en las relaciones sociales de los individuos y en las formaciones sociales en las que están involucrados 
(Dávila, 2004). Sin embargo, como se podrá ver más adelante, las y los participantes utilizan ambos conceptos de dos maneras: una, de forma indistinta o como sinónimos, y dos, como dos etapas diferentes de maduración donde la adolescencia antecede a la juventud. De acuerdo con dicha lógica, se presentan los resultados en función de la categoría en la cual se ubican, los atributos que se le asignan y los criterios para distinguirlas.

Una definición frecuentemente utilizada para referirse a las personas en las edades de las y los participantes es la adolescencia. Este último concepto deriva del latín adolescere que significa "crecer hacia la adultez" (Gaete, 2015). La adolescencia, vista de una perspectiva biologicista, es una etapa de desarrollo que sigue a la infancia y antecede a la adultez, en la cual ocurre un proceso de maduración física, psicológica y social (Gaete, 2015). En relación con esta concepción, una de las participantes afirmó:

Valeria (18 años). Siento que sigo siendo adolescente pero sí siento que he madurado un poquito más con todo eso de mi bebé, obviamente sigo siendo adolescente porque sigo... siento... quiero salir y divertirme, en ese aspecto siento que todavía no estoy tan adulta para hacer esas cosas y me doy cuenta que no soy tan madura.

Valeria, quien es madre, vinculó la adolescencia con la inmadurez y con las "cosas" que realiza un adolescente. De acuerdo, con lo que dice Valeria, entre esas cosas que hace una adolescente está salir con amigos y divertirse. Sin embargo, estos atributos se alternan por su maternidad, es decir, considera que ser madre le ha ayudado a madurar. En relación con "lo que hacen los adolescentes" y qué los define, dos participantes mencionaron:

Patricia (17 años). Joven, más bien una adolescente, porque tengo 17 años, porque estoy viviendo situaciones que un joven común como yo vive... una etapa en la que empiezas a madurar a darte cuenta de los problemas que, este... pues sociales que tu familia normalmente tiene y que cuando eras niña no comprendías... problemas de lo que quiero ser cuando sea grande, qué quiero hacer con mi vida, si quiero tener hijos, pues más bien responsabilidades, por ejemplo, de darme algunos gustos que yo sé que no puedo tenerlos por parte de mi familia, que yo tengo que conseguirlos por mí misma.

Heidi (18 años). Siento que adolescente porque aún no estoy tan madura, por la edad, bueno no tanto por mi edad, sino por la forma como soy, aparte que también vengo a la escuela... Soy una persona alegre, me gusta hacer vagancias, estar platicando, estar... salir con mis amigas. Aparte, todavía no tengo toda la responsabilidad de madre, como de trabajar, cuidarla (a su hija) todo el tiempo. 
De acuerdo con lo que mencionaron las dos participantes anteriores, se pueden identificar algunos de los criterios utilizados para definir la adolescencia, tales como la edad y la escolaridad. Sin embargo, también se mencionan algunos atributos que dan cuenta que en dicha etapa se empieza a "madurar" y "a darse cuenta" de los problemas. Estos últimos procesos parecen estar fuertemente vinculados con los intereses y proyectos de vida.

En cuanto a las y los participantes que se asumieron como jóvenes, lo hicieron por diversos criterios como la edad, el nivel escolar que cursaban, la superación de la adolescencia y el inicio o estar en un proceso de maduración, que los situaba en esa etapa vital. En otras palabras, juventud implicaría tener algunas responsabilidades pero no tantas como un adulto, y no ser tan "inmaduros" para ser considerados como niños o como adolescentes.

Karla (17 años). Joven, siento que la etapa de adolescente es cuando estás en la secundaria, sí, ya cuando tienes de 17 a 18 años.

Alejandro (17 años). ...Jovén, porque no sé... ya ha cambiado mucho mi forma de pensar... empiezas a ver como otro punto de vista, como si algo ya me va a afectar.

Victor (16 años). Joven, porque yo digo que adolescente ya no, ya pasé esa etapa... ya estoy en un proceso más de maduración, no soy un adulto, pero sí me considero un joven... [¿En qué consiste esa maduración?] En la forma de pensar, la forma de platicar con mis amigos, en la forma en la que hago las cosas, en lo que hago... Antes era más de lo que hacíamos llegando a la casa, jugar xbox, cualquier cosa así. Ahora cuando estamos en grupo ya platicamos de las tareas, de los trabajos, yo creo que es un proceso de más maduración.

Dana (17 años). Como una joven. No me considero ni tan niña, ni siento que sea tan grande. Por la responsabilidades, yo trabajo, tengo que organizar dinero porque mi mamá ya no me da dinero, lo tengo que organizar. Los jóvenes se divierten, estudian.

Solo un participante se asumió como adulto, refirió haber superado la inmadurez que muestran los adolescentes y los jóvenes. Manuel se consideró a sí mismo como adulto "pues no tengo así rasgos, por ejemplo, de joven, siento que ya los dejé de lado".

Como se puede observar, el uso de los términos adolescencia y juventud fue difuso. Sin embargo, y de manera general, se pudo observar que las y los participantes se consideran a sí mismos como personas en transición entre la niñez y la adultez. Esta etapa que dicen vivir se caracteriza por procesos de maduración, adquisición de responsabilidades, tener cierto rango de edad y cursar un determinado nivel escolar. Todos estos atributos están adscritos a una visión adultocentrista de la juventud.

El adultocentrismo es una categoría que designa las relaciones asimétricas y tensionales de poder entre adultos y jóvenes. Esta visión está ubicada en un orden simbólico y de valores propio de una concepción patriarcal. El criterio biológico subordina o excluye a las mujeres por 
razón de sexo y a los jóvenes por la edad (Krauskopf, 1998). El adultocentrismo sustenta la representación de que los adultos son un modelo acabado al que se aspira, para el cumplimiento de las tareas sociales.

De acuerdo con Krauskopf (1998), desde esta categoría se orientan los programas y políticas para la protección de las y los jóvenes en términos de salud sexual. Así como el enfoque de género dejó al descubierto el sexismo, un enfoque moderno de juventud deja al descubierto los problemas específicos que se presentan actualmente en las relaciones intergeneracionales (Krauskopf, 1998) y que dificultan el ejercicio de la sexualidad, de los derechos sexuales y, por ende, la subjetivación del sujeto de derechos.

En relación con el ejercicio de la sexualidad, se les cuestionó a las y los participantes si las y los jóvenes pueden actuar responsablemente. La mayoría de participantes mencionaron que sí, dos de ellos lo atribuyeron a las experiencias y a la educación sexual (formal e informal) como vías para desarrollar dicha responsabilidad.

Patricia (17 años). Edad... no sé... desde la secundaria que nos enseñan todo esto, que nos hablan de todo esto, todos los problemas que hay, llegas a una madurez cuando lo vives o cuando lo ves, por ejemplo, cuando ves a una prima que está embarazada y ves cómo le batalla pues ahí igual, o bueno, si a mi me pasa que tenga un descuido, que no use condones y esté toda preocupada, pues ahí es cuando ya es cierto lo que dice la gente.

Karla (17 años). Sí, pero depende de la madurez de cada persona ¿no? Yo siento que no todos estamos preparados porque no todos somos capaces como de llevar como la responsabilidad de que si algo pasa, o sea, hacerlo bien... A lo mejor con educación que te dan tus papás, siento que es eso. Pues porque ahora desde chicos nos enseñan educación sexual y pues siento que están más abiertos al tema y ya no están como tan preocupados de lo que digan las demás personas.

Dos participantes agregaron que para desarrollar la responsabilidad en el ejercicio de la sexualidad se involucra la capacidad reflexiva que puede derivar de las enseñanzas informales y de las experiencias propias y las de los otros.

Alejandro (17 años). Sí y no, hay personas inmaduras que no se la piensan para hacer las cosas... A lo mejor con el tiempo, con las experiencias que vives. No con la edad, las personas que son más chicas que otras y somos más maduras que otras, porque a lo mejor les contaron algo y se pusieron a pensar.

Heidi (18 años). Yo creo que no hay edad, cada persona madura a su tiempo. 
Por otra parte, dos participantes mencionaron lo contrario, y desde una perspectiva biologicista afirmaron que las personas debieran tener relaciones sexuales hasta alcanzar un cierto nivel de madurez.

Dana (17 años). No es correcto [tener relaciones sexuales] a nuestra edad... siendo mayor de edad... ya estás un poco más maduro, ya es la edad donde tomas tus propias decisiones.

Manuel (17 años). Madurez emocional... que es variable, pero no por la edad... Para tener relaciones no hay una edad cierta, desde mi punto de vista... Siempre hay algo a su tiempo... A esta edad no es muy conveniente tener relaciones... el estrés, no es tan verdadero el amor, cambios hormonales.

Lo que mencionan tanto Dana como Manuel evidencia una concepción de jóvenes como seres que no pueden controlar sus impulsos y que por lo tanto, no pueden tomar sus propias decisiones.

\section{Elementos curriculares enfocados a la formación del sujeto de derechos sexuales}

Más arriba se puntualizó que la formación del sujeto de derechos sexuales desde la educación formal, se puede realizar a través de la integración de objetivos, ejes trasversales, asignaturas y temáticas. A continuación se realiza la identificación de estos elementos para el caso de la institución a la que pertenecen las y los participantes de la investigación.

El Bachillerato General por Competencias de la Universidad de Guadalajara es un programa de educación perteneciente al medio superior, es formativo y propedéutico (SEMS-UDG, 2009). El BGC, orientado hacia el constructivismo, trabaja con el enfoque por competencias y busca desarrollarlas en los ámbitos científico, tecnológico, social, cultural y laboral (SEMS-UDG, 2009). El BGC adopta principios orientadores tales como educación para la libertad, la paz y el pensamiento crítico.

El diseño curricular del BGC está integrado por competencias genéricas y específicas. Las primeras se refieren a los atributos que debe tener cada estudiante al finalizar el plan de estudios y se abordan mediante ejes. Las segundas se refieren a los aspectos mínimos necesarios de cada campo disciplinar y se trabajan a través de asignaturas o unidades de aprendizaje. Tanto las competencias genéricas como específicas se expresan en conocimientos, habilidades, actitudes y valores.

De acuerdo con el plan de estudios del BGC, los egresados deben desarrollar ciertas competencias y atributos. Considerando la temática de la investigación, a continuación se presentan algunas que se consideran relevantes: 
- Identidad. Diseñar y emprender proyectos con base en su autoconocimiento, autoestima, pensamiento ético y respeto a la diversidad.

- Autonomía y liderazgo. Desarrollar competencias de autonomía y liderazgo para la toma de decisiones, enfrentamiento de riesgos y resolución de conflictos.

- Ciudadanía. Proponer soluciones a problemas de la sociedad de manera proactiva, solidaria y cooperativa, con un alto sentido de responsabilidad y justicia con respecto a diversidad. Desarrollar tareas que le permitan ejercer su autonomía y autogestión en la toma de decisiones, siempre con una postura ética y solidaria.

- Pensamiento crítico. Sustenta una postura personal, integra informalmente diversos puntos de vista y utiliza su capacidad de juicio.

- Vida sana. Adopta estilos de vida sana asumiendo conscientemente su bienestar físico y emocional. Mantiene una actitud proactiva en la prevención y tratamiento de enfermedades.

El plan de estudios del BGC está integrado por cinco ejes curriculares o competencias genéricas: comunicación, pensamiento matemático, comprensión de la naturaleza, comprensión del ser humano, ciudadanía y formación para el bienestar (SEMS-UDG, 2009). En cuanto a los ejes que podrían contribuir a la formación del sujeto de derechos sexuales, se considera que son los últimos dos.

El eje "Compresión del ser humano y ciudadanía" contribuye a que las y los estudiantes desarrollen dos aspectos: asumirse como seres capaces de construir su entorno, su vida y su mundo, y valorar sus capacidades para crear-trasformar-actuar mediante la convivencia. Este eje ayuda a desarrollar competencias en los siguientes sentidos: a) Pensamiento ético, se fomenta el autorreconocimiento como sujeto ético, libre y responsable de sus actos; b) Personalidad, el alumno tendrá un carácter integrador pues podrá conocer su desarrollo personal, construir su autoestima, comprender su sexualidad y sus vínculos afectivos con los demás; c) Ciudadanía, se desarrollarán habilidades, conocimientos, valores y actitudes que ayudarán a las y los estudiantes para su reconocimiento como futuros ciudadanos.

En las asignaturas incluidas en el eje "Compresión del ser humano y ciudadanía", se encuentran tres que llaman la atención: "Formación ciudadana", "Ciudadanía mundial"y "Reflexión ética".

En materia de formación ciudadana, se tiene planeado realizar una revisión de las consideraciones generales relativas a la ciudadanía (derechos y obligaciones), además de desarrollar en las y los estudiantes las siguientes competencias específicas: que se asuman como "individuos de derechos y obligaciones", ${ }^{13}$ que participen activamente de la diversidad de formas de orga-

13 En el programa de estudios de la asignatura de "Formación ciudadana" no se hace una definición del concepto "individuo de derechos", ni tampoco se establece una distinción entre el respectivo a "sujeto de derechos". Sin embargo, la lectura que se le da al primer concepto, te- 
nización social, que debatan sobre sus derechos y obligaciones para mejorar su entorno y su calidad de vida, y que propongan posibles alternativas de mejora a los problemas que enfrenta el ciudadano contemporáneo (SEMS-UDG, 2011b).

En la asignatura de ciudadanía mundial se tiene el objetivo de que las y los estudiantes se asuman como ciudadanos mundiales activos y responsables. Algunos de los conocimientos que adquirirán son las definiciones de discriminación, racismo, segregación y tolerancia (SEMS-UDG, 2011c).

En cuanto a la materia de reflexión ética, se propone que las y los estudiantes reflexionen acerca de las ideas morales que determinan los modos de convivencia humana. Además, se busca que problematicen los dilemas éticos (SEMS-UDG, 2011d).

El eje "Formación para el bienestar" tiene los propósitos de la promoción, el fortalecimiento de estilos de vida sanos, y la consolidación de la identidad y pertenencia a grupos sociales (SEMS-UDG, 2009). Algunas de las competencias que se desarrollan en este eje son las siguientes: comprensión de la sexualidad y la vinculación afectiva, construcción de condiciones para la comprensión y el manejo de una sexualidad sana y adopción de estilos de vida sanos.

En este mismo eje transversal se encuentra "Sexualidad humana". En esta asignatura se pretende brindar información y desarrollar habilidades, actitudes y valores sobre diferentes aspectos que les permitan tomar decisiones asertivas para el ejercicio de la sexualidad. Entre las temáticas a revisar en dicho curso se encuentran: el amor, la pareja y el erotismo, la violencia, métodos anticonceptivos, riesgos de un ejercicio irresponsable de la sexualidad, prevención de embarazos, infecciones y enfermedades de trasmisión sexual, y los derechos sexuales (SEMS-UDG, 2011a).

En conclusión, el plan de estudios del BGC contiene varios elementos que podrían contribuir a la formación del sujeto de derechos sexuales. Los propósitos, ejes, asignaturas y temáticas —al menos en el sentido formal- están orientados y alineados a difundir información, desarrollar habilidades y fomentar actitudes y valores que son congruentes con las características atribuidas al sujeto de derechos sexuales.

\section{Conclusiones}

El estudio tuvo el objetivo general de conocer de qué manera las y los jóvenes estudiantes de una preparatoria del BGC del SEMS de la UDG devienen sujetos de derechos sexuales, y específicamente para este trabajo, a partir de los significados atribuidos a la sexualidad y al "ser joven" en su relación con el ejercicio de esta. Además, se buscó identificar los elementos del currículo formal que están enfocados a formar sujetos de derechos sexuales.

niendo en cuenta el resto del contenido del programa, es que se refiere al hecho que las y los estudiantes se podrán asumir como personas que tienen derechos y obligaciones; una concepción que sería, en términos generales, similar a la que se está manejando en la presente investigación (sujeto de derecho).

Diálo os 
Partiendo de los objetivos de investigación, se presentan conclusiones por cada uno de estos $y$, posteriormente, se exponen las respectivas al objetivo general.

Los significados atribuidos a la sexualidad son híbridos ya que en estos se intersectan una diversidad de discursos. Por una parte, desde una perspectiva hegemónica, la sexualidad se relacionó con el sexo biológico y las relaciones sexuales. En otras palabras, estos significados se adscriben al sistema dicotómico (hombre/mujer) y a una conceptualización de la sexualidad coitocéntrica y heteronormada. Por otra parte, se manifestaron algunas posturas con una perspectiva integral de la sexualidad, que si bien incluían el sexo biológico y las relaciones sexuales heterosexuales, también se incorporaron las preferencias sexuales, el género y la afectividad.

Las y los participantes del estudio se asumieron jóvenes o adolescentes de forma indistinta, a pesar de ello, los atributos asignados se adscriben a una perspectiva biologicista. Esta última — sustentada en el adultocentrismo - indica que las y los jóvenes viven una etapa de maduración y que aún no están preparados para ejercer de manera responsable su sexualidad. Esta postura es asumida tanto por las y los jóvenes entrevistados. De tal manera que sus experiencias sexuales se perciben como riesgosas y para realizarlas debieran -en un sentido ideal- esperar una cierta madurez. Para lograr esta última, se atribuyó una gran importancia a los eventos vitales tales como las experiencias sexuales y la educación en sexualidad.

En relación con los elementos curriculares, se identificó que existe un alineamiento entre los diferentes elementos del currículo (objetivo general, ejes, asignaturas y contenidos) que pueden contribuir a la formación del sujeto de derechos sexuales. Aunque las y los participantes reconocieron que la educación formal (en secundaria y preparatoria) influye en la toma de decisiones y en la madurez, es difícil determinar si los contenidos revisados están relacionados con ello. Se considera relevante indagar sobre cuestiones pedagógicas y de cultura escolar para saber cómo estos contenidos se implementan, se viven y el impacto que tienen en la comunidad estudiantil.

Ahora bien, a partir de los hallazgos, es momento de responder una pregunta: ¿de qué manera las y los jóvenes entrevistados han devenido sujetos de derechos sexuales? Previamente, en el marco teórico se precisó que la subjetivación y visualización del sujeto de derechos sexuales podría ser momentánea, efímera. En el caso de las y los jóvenes estudiantes entrevistados, partiendo de sus voces, podría decirse que dicho proceso se está configurando, que no es permanente ni fijo, pero que se manifiesta. ¿Pero en qué momentos se visualizan?

En los significados atribuidos a la sexualidad y al "ser joven" se reflejan la intersección e hibridación de diversos discursos. Si bien sigue imperante una perspectiva hegemónica heteronormativa y adultocentrista, tanto de la sexualidad como de la juventud respectivamente, es evidente la presencia de otros discursos como el de sexualidad integral y de derechos, que contribuyen a generar otras posibilidades. Se visibilizan como tales cuando refieren una distinción entre sexualidad y reproducción, cuando asignan y cuestionan las funciones de cada una 
de estas y también cuando destacan la responsabilidad en las prácticas sexuales a pesar de su edad, de cierta inmadurez o de impulsos.

\section{Referencias}

Amorín, D. (2007). Adultez y masculinidad. La crisis después de los 40. Venezuela: Psicolibros-Waslala.

Amuchástegui, A. (2001). Virginidad e iniciación sexual, experiencias y significados. México: EDAMEX / Population Council.

Amuchástegui, A.; M. Rivas (2004). Los procesos de apropiación subjetiva de los derechos sexuales: Notas para la discusión. Estudios Demográficos y Urbanos, (57), 543-597. México: El Colegio de México. http://www.catedradh.unesco.unam.mx/SeminarioCETis

Amuchástegui, A. (2005). Condiciones de posibilidad para el ejercicio del derecho al aborto: discursos sociales, leyes y relaciones sexuales. Desacatos, (17), 77-82. http://www.redalyc. org/pdf/139/13901705.pdf

Amuchástegui, A.; M. Rivas (2005). Los procesos de apropiación subjetiva de los derechos sexuales: notas para la discusión. Estudios Demográficos y Urbanos (57), 543-597. México: El Colegio de México. https://estudiosdemograficosyurbanos.colmex.mx/index.php/edu/article/view/1181/1174

Amuchástegui, A.; M. Rivas (2008). Construcción subjetiva de la ciudadanía sexual en México. En I. Szasz, I.; G. Salas. Sexualidad, derechos humanos y ciudadanía. Diálogos en torno a un proyecto de construcción. México: El Colegio de México, 57-133.

Alpízar, L.; M. Bernal (2003). La construcción social de las juventudes. Última Década. (19), 1-20. http://www.scielo.cl/scielo.php?script=sci arttext\&pid=S0718-22362003000200008

Alva, R. (2006). ¿"Hagamos un hecho nuestros derechos"? Actitudes de jóvenes de Iztapalapa hacia sus derechos sexuales y reproductivos. Tesis de Maestría en Estudios de Género. México: El Colegio de México.

Bauman, Z. (2002) Modernidad líquida. Argentina: FCE.

Butler, J. (2007). El género en disputa. El feminismo y la subversión de la identidad. España: Paidós. Cabral, B. (2008). Mujeres, conciencia de género y participación política. Fermentum, Revista Venezolana de Sociología y Antropología, 18(53). http://www.redalyc.org/articulo. oa?id=70517572004

Castro, R. (2008). Foucault y el cuidado de la libertad: ética para un rostro de arena. Chile: LOM Ediciones.

CDM (2006). Ejercicio de derechos sexuales y reproductivos en adolescentes. http://www.corteidh. or.cr/tablas/26286.pdf 
Checa, S. (2003). Aproximaciones a la problemática de la sexualidad adolescente. En Checa, S. (comp.). Género, sexualidad y derechos reproductivos en la adolescencia. Buenos Aires: Paidós, 19-36.

Checa, S. (2006). Salud y derechos sexuales y reproductivos. Encrucijadas, (39), 10-15. Buenos Aires: UBA. http://www.uba.ar/encrucijadas/nuevo/pdf/encrucijadas39n3.pdf

Connell, R. W. (2002). Gender. Cambridge: Polity Press.

Correa, S.; R. Petchesky (2001). Los derechos reproductivos y sexuales: una perspectiva feminista. En Figueroa, J. G. (ed.), Elementos para un análisis ético de la reproducción. México: PUEG / UNAM / Porrúa.

Dávila, O. (2004). Adolescencia y juventud: De las nociones a los abordajes. Última Década (21), 83-104. https://www.redalyc.org/pdf/195/19502103.pdf

Di Pasquale, V. (2010). Género, subjetividad y educación. Revista Electrónica de Psicología Política, 8(23). 50-71. http://www.psicopol.unsl.edu.ar/Agosto2010 Nota2.pdf

Figueroa, J. G. (2005). Algunos dilemas éticos y políticos al tratar de definir los derechos reproductivos en la experiencia de los varones. Perspectivas Bioéticas, 10(18), 53-75. http:// menengage.org

Foucault, M. (1988). El sujeto y el poder. Revista Mexicana de Sociología, 50(3) 3-20.

Foucault, M. (1998). Historia de la sexualidad 1. La voluntad de saber. México: Siglo XXI Editores.

Foucault, M. (1999). Estética, ética y hermenéutica. España: Paidós.

García, L. (2014). Una aproximación a los derechos sexuales y reproductivos en jóvenes: Un análisis desde la perspectiva de género. Tesis de Licenciatura en Psicología. UNAM, México.

Gaete, V. (2015). Desarrollo psicosocial del adolescente. Revista Chilena de Pediatría, 86(6). 436443. http://www.scielo.cl/pdf/rcp/v86n6/art10.pdf

Granados, J. A. (2002). Orden social y alteridad. Nueva Antropología. Revista de Ciencias Sociales, (61), 79-97. https://www.google.com.mx/\#q=Orden+social+y+alteridad

Gutiérrez, M. A. (2003). Derechos sexuales y reproductivos de los adolescentes: Una cuestión de ciudadanía. En S. Checa, Género, sexualidad y derechos reproductivos en la adolescencia. Argentina: Paidós, 77-98.

Hernández, J.; E. Weiss (2010). Amor y sexualidad entre jóvenes de la educación media en México. Cuadernos de Educación, 8(8). http://campus.ajusco.upn.mx:8080/upn/handle/11195/34

Juárez, L. (2009). Apropiación de derechos sexuales y reproductivos en la adolescencia: dimensiones de la ciudadanía. Revista de Estudios de Género: La Ventana, 4(30), 148-180. Guadalajara: Universidad de Guadalajara. http://www.scielo.org.mx/scielo.php?script=sci arttext\& pid=S1405-94362009000200007

Kaufman, M. (1995). Los hombres, el feminismo y las experiencias contradictorias del poder entre los hombres. http://www.michaelkaufman.com/wp-content/uploads/2008/12/los-hombres-el-feminismo-y-las-experiences-contradictorias-del-poder-entre-los-hombres.pdf 
Krauskopf, D. (1998). Dimensiones críticas en la participación social de las juventudes. En Participación y desarrollo social en la adolescencia. San José: Fondo de Población de Naciones Unidas. http://bibliotecavirtual.clacso.org.ar/ar/libros/cyg/juventud/krauskopf.pdf

Kvale, S. (2011). Las entrevistas en investigación cualitativa. Madrid: Ediciones Morata.

Lamas, M. (2016). Nuevos valores sexuales. Debate Feminista, 8(16). http://www.debatefeminista.cieg.unam.mx/df ojs/index.php/debate feminista/article/view/409/347

López, A.; C. Güida (2002). Aportes de los estudios de género en la conceptualización sobre masculinidad. http://catedra-laicidad.unam.mx/detalle-articulos-de-interes/249/Aportesde-los-estudios-de-género-en-la-conceptualización-sobre-masculinidad

Lozano, M. (2008). Los procesos de subjetividad y participación política de estudiantes de psicología de Bogotá. Revista Diversitas-Perspectivas en Psicología, 4(2), 345-357. http://pepsic. bvsalud.org/pdf/diver/v4n2/v4n2a11.pdf

Maffía, D. (s.f.). Derechos sexuales y reproductivos: Algo más que procreación. http://dianamaffia.com.ar/archivos/Derechos-sexuales-y-reproductivos.-Algo-más-que-procreación. pdf

Maffía, D. (2012). Los CHB y el derecho a la salud sexual y reproductiva. http://www.cba.gov.ar/ wp-content/4p96humuzp/2012/08/maffia.pdf

Magendzo, A. (2001). El derecho a la educación: Una reflexión desde el paradigma crítico y la educación en derechos humanos. http://www.cifedhop.org/Fr/Publications/Thematique/ thematique9/Magendzo.pdf

Magendzo, A.; T. Toledo (2009). Educación en derechos humanos. Estudios Pedagógicos, 35(1), 139-154. http://www.scielo.cl/pdf/estped/v35n1/art08.pdf

Mantilla, A. (1996). Género: Variable clave en educación sexual. Bogotá: Fundación Gamma Idear.

Mesa, A. (2006). Marco internacional y nacional de los derechos sexuales en adolescentes. Comisión de Derechos Humanos del Distrito Federal. México: Afluentes.

Miyares, A. (2003). Democracia feminista. En A. Miyares, Democracia feminista. Valencia: Ediciones Cátedra, 161-209.

Morgade, G. (2006) Educación en la sexualidad desde enfoque de género. Una antigua deuda de la escuela. Novedades Educativas, (184), 40-44. https://educacion.rionegro.gov.ar/contenidosmultimedia/wp-content/uploads/2013/03/Educacion-en-la-sexualidad-desde-elenfoque-de-género.-Morgade.pdf

Olivares, E.; M. Trejo (2010). Diagnóstico sobre derechos sexuales y reproductivos de las y los jóvenes indígenas del Estado de Hidalgo. México: Instituto Hidalguense de las Mujeres. http://cedoc. inmujeres.gob.mx/ftpg/Hidalgo/hgometa14.pdf

Oyarzún, P. (2006). Importancia de las infecciones de transmisión sexual en adolescentes. Ponencia en el Congreso de Obstetricia, Ginecología infantil y Adolescencia. Santiago. http:// www.medwave.cl/link.cgi/Medwave/PuestaDia/Congresos/1264 
Quintana, A. (2006). Metodología de investigación científica cualitativa. En Quintana, A.; W. Montgomery (eds.). Psicología: Tópicos de actualidad. Lima: UNMSM.

Packer, M. (2013). Introducción. En Packer, M. La ciencia de la investigación cualitativa. Bogotá: U. de los Andes, 1-8.

Pérez, F. (2007). Salud: Jóvenes y derechos sexuales y reproductivos. En CEPAL. Informe sobre la situación de los derechos humanos en Jalisco. Jalisco: Inkoprint, 35-42. http://redtdt.org.mx

Petchesky, R.; K. Judd (2006). Cómo negocian las mujeres sus derechos en el mundo. México: El Colegio de México.

Ragin, C. (2007). La construcción de la investigación social. Introducción a los métodos y su diversidad. Bogotá: Siglo del Hombre Editores.

Ramos, V. (2011). Derechos sexuales y reproductivos en adolescentes de Montevideo. Tesis de Maestría en Género, Sociedad y Políticas. Argentina: FLACSO.

Ramos, M.; E. Vásquez (2005). Derechos sexuales y reproductivos. El punto de vista de los varones en dos contextos del Perú. En Pantelides, E. A.; E. López (eds.). Varones latinoamericanos. Estudios sobre sexualidad y reproducción. Buenos Aires: Paidós.

Rivas, M. (2004a). Sexualidad, género y subjetividad femenina. Anuario de Investigación 2003, 558-572. México: UAM. http://148.206.107.15/biblioteca digital/capitulos/37-1323mfo.pdf

Rivas, M. (2004b) La relación entre la apropiación subjetiva y los derechos reproductivos y sexuales. Genérica (5). generomexico.colmex.mx/textos/marta \%20rivas.doc

Rodríguez, Y. (2007). Los derechos sexuales de las y los jóvenes en el contexto nacional e internacional. Revista del Instituto de Ciencias Jurídicas de Puebla, 211-243. http://www.redalyc. org/pdf/2932/293222932012.pdf

Roncal, D.; M. Carranza (2012). Conocimiento y percepción sobre derechos sexuales y reproductivos de los estudiantes de la Universidad Privada Antenor Orrego. Revista del Cuerpo Médico Hospital Nacional Almanzor Aguinaga Asenjo, 5(3), 7-12. https://dialnet.unirioja.es/ servlet/articulo?codigo $=4040351$

Sánchez, A. (2009). Adolescentes y educación sexual. En Sánchez, A. Derechos sexuales y reproductivos en México. México: UNAM.

SEMS-UDG (2009). Bachillerato General por Competencias del Sistema de Educación Media Superior de la Universidad de Guadalajara. Jalisco: UDG.

SEMS-UDG (2011a). Programa de la unidad de: Sexualidad humana. Jalisco: UDG.

SEMS-UDG (2011b). Programa de la unidad de: Formación ciudadana. Jalisco: UDG.

SEMS-UDG (2011c). Programa de la unidad de: Ciudadanía mundial. Jalisco: UDG.

SEMS-UDG (2011d). Programa de la unidad de: Reflexión ética. Jalisco: UDG.

Scott, J. (1990). El género: útil para el análisis histórico. En Nash, M.; J. S. Amelang (eds.), Historia y género: las mujeres en la Europa moderna y contemporánea. Valencia: Alfons el Magnanim. 
Serrano, J. (2002). Ni lo mismo ni lo otro: La singularidad de lo juvenil. Nómadas, (16), 10-25. Colombia.http://www.redalyc.org/pdf/1051/105117941002.pdf

Sonderéguer, M. (2002). El derecho a tener derechos en la nación argentina. Red Universitaria sobre Derechos Humanos y Democratización para América Latina, 2(3). http://www.unsam. edu.ar

Stern, C. (2008). Adolescentes en México. México: El Colegio de México.

Strauss, A.; J. Corbin (2002). Introducción. En Strauss, A. Bases de la investigación cualitativa. Técnicas y procedimientos para desarrollar la teoría fundamentada. Colombia: Universidad de Antioquia, 1-16.

Taylor, S.; R. Bogdan (1994). Introducción. Ir hacia la gente. En Taylor, S.; R. Bogdan (eds.). Introducción a los métodos cualitativos (15-27). Bogotá: Paidós.

Touraine, A. (2006). ¿ ¿Podremos vivir juntos? México: FCE, 61-97.

Valenzuela, E.; L. Casas (2007). Derechos sexuales y reproductivos: confidencialidad y VIH/SIDA en adolescentes chilenos. Acta Bioethica, 12(2), 207-215. http://www.scielo.cl/scielo

Vance, C. (1984). Pleasure and danger. USA: Routledge \& Kegan Paul.

Villa, A. (2007). Cuerpo, sexualidad y socialización. Intervenciones e investigaciones en salud y educación. Argentina: Noveduc.

Weeks, J. (1998). Sexualidad. México: Paidós mexicana.

Weeks, J. (2015). Conferencia magistral en el Foro sobre educación integral en Sexualidad. http://www.gob.mx/sep/prensa/comunicado-358-trabaja-sep-en-la-educacion-integralen-sexualidad?state $=$ published 